\title{
Representações de crianças sobre a natureza a partir de uma perspectiva ecológica - afetivamente ampliada - da vida ${ }^{1}$
}

Children's representations about nature based on an affectively extended ecologic perception of life

Helga Loos-Sant'Ana*

Universidade Federal do Paraná

Camila Silva de Lima**

Universidade Federal do Paraná

Resumo Defende-se, neste artigo, que o ser humano volte a ser capaz de desenvolver um sentimento de pertencimento à Natureza e que a educação ambiental não seja apenas um conjunto de atividades informativas relativas à "utilização racional dos recursos da Natureza". O presente estudo objetivou, por meio de técnicas qualitativas (desenhos e dinâmicas de grupo), identificar representações e afetos relacionados à Natureza entre nove estudantes da $1^{\mathrm{a}} \mathrm{e} 2^{\mathrm{a}}$. séries do Ensino Fundamental, no município de Curitiba/PR. Foi evidenciada uma visão naturalista da Natureza e a ligação biofílica e topofílica das crianças com o bosque da escola. Notam-se, porém, conflitos relativos à questão do pertencimento do homem e de seus produtos à Natureza. Tais tipos de atividades, na escola, mostramse importantes para o desenvolvimento de relações saudáveis com o meio ambiente.

PALAVRAS-CHAVE: Educação Ambiental, Afetividade, Representações.

Abstract This article is supported by the perspective that mankind should relearn how to develop a feeling of belonging to Nature, and that environmental education should be seen not only as a group of informative activities aiming at "rational use of Nature's resources". The current study was aimed at identifying, by qualitative techniques (drawings and group dynamics), representations and affects related to Nature among nine students of 1 st and 2 nd grades of a Elementary School, in the city of Curitiba/PR/Brazil. Results presented a naturalist view of Nature, and the biophilic and topophilic relations of the children with the school's grove. However, conflicts were observed relating to the belonging of mankind and their products to Nature. Such activities at school seem to be very important for the development of healthy relationships with the environment.

KEYWORDS: Environmental Education, Affectivity, Representations. 


\section{A crise ambiental é uma crise relacional - portanto, do âmbito da afetividade}

É possível observar que, ao longo da história da filosofia da Natureza, existiu uma oscilação permanente entre duas tendências opostas: uma que pensa a Natureza como divina, animada, um imenso organismo vivo; e outra que a concebe como uma grande máquina, secularizada e desprovida de alma (GONÇALVES, 2008). Na passagem de uma visão à outra, ocorreu o que se denomina "desnaturalização da Natureza", pois esta foi transformada em fonte de recursos, dentro do fluxo unidimensional da produtividade econômica (LEFF, 2006). A partir de então, explica Leff (2001), gerou-se uma crise na relação homem-natureza, a qual faz parte de um modelo regido pelo predomínio da razão tecnológica e científica moderna, que promoveu a tecnologização da vida e a economização da Natureza. Valores naturais e universais foram substituídos por valores subjetivos individuais e pessoais, transformando bens de uso coletivo em bens de negócio e livre mercado. Para Leff (2000a), a dinâmica produtiva e acumulativa da economia capitalista "gera um processo entrópico, desestruturador do ambiente e oposto à vida como um processo permanente de auto-organização e de diferenciação." (p. 355). De fato, a vida vem sendo tiranizada por nossa forma de viver, e como denota Unger (1991), "pode-se dizer que o projeto da modernidade é o de tiranização da vida, de tiranização da realidade, em que nos tornamos escravos de nosso próprio desejo ilusório de tudo controlar e tudo dominar." (p. 35).

Os diversos e interdependentes problemas surgidos desta falta de relação adequada com a Natureza envolvem processos sociais, políticos, econômicos e culturais, bem como uma multiplicidade de atores sociais com diferentes noções e interesses acerca das formas de resolução que poderiam ser encaminhadas (FREITAS, 2003). E é, considerando estas noções e interesses, que os estudos acerca da percepção e da representação ambiental comumente se dirigem. Entretanto, devemos lembrar que tais processos também são permeados pelas emoções e sentimentos de tais atores sociais e estes possuem influência decisiva no encaminhamento das possíveis soluções. Deseja-se, no presente trabalho, enfatizar que se não procurarmos resgatar o envolvimento afetivo do ser humano com o ambiente - e, nesse caso, trata-se de uma afetividade "ampliada" - não sairemos da ilusória certeza que a tecnologia resolverá todos os nossos problemas. E, conforme dito por Reigota (1994a), estes problemas foram criados por mulheres e homens, e é deles que deverão vir as soluções.

\section{O papel da Educação na redefinição de nossa afetividade para com a natureza}

Pode-se considerar que "toda educação é uma educação ambiental [...] com a qual, por inclusão ou exclusão, ensinamos aos jovens que somos parte integral ou separada do mundo natural." (ORR, 2006b, p. 140). Esse direcionamento do desenvolvimento humano, mediado pela educação, é permeado fundamentalmente pelas emoções (aquilo que nos põe em movimento) que, para Capra (2006), estimulam e apoiam o entendimento intelectual da ecologia. Por este motivo, a educação, por uma vida sustentável ${ }^{2}$, tem muito mais chances de fazer com que as crianças se tornem cidadãos responsáveis e realmente preocupados com a sustentabilidade da vida. 
Segundo Hutchison (2000), uma abordagem ecologicamente sensível da educação, principalmente com crianças durante a fase da segunda infância, também incorpora uma visão espacial do universo, enraizada no estudo do lugar e da natureza. Dentro desta proposta, devem ser explorados os sentimentos de biofilia e de topofilia, por exemplo. Entende-se por "biofilia" a afinidade com outras formas de vida, com a terra, com a água, com o solo e o com o lugar (MARIN, 2003; ORR, 2006a). Já a "topofilia" é, segundo Tuan (1980), um elo afetivo entre o lugar e a pessoa, o qual é responsável pela forma como ela o ocupa e vivencia. $\mathrm{O}$ autor explica que o ambiente não é o único responsável pelo surgimento do sentimento topofílico, mas fornece os estímulos sensoriais que, ao agirem como imagem percebida, dão formas às alegrias e aos ideais humanos. Os processos cognitivos, no nível da informação, têm o papel de complementar a sensibilização, tornando-a consciente e declarada. Não conseguiríamos nos sentir ligados à rede da vida focando somente em processos lógico-formais, "pois se trata de re-ligar o corpo, o pensamento e o comportamento."(SARDI, 1999, p. 159).

E é, nesse sentido, que se enfatiza aqui a importância da afetividade. A afetividade, como comumente se entende, diz respeito aos processos complexos que abrangem as emoções, os humores e as disposições (OATLEY; JENKINS, 2002). Porém, a noção de afetividade pode e deve ser ampliada, já que ela envolve, sobretudo, a qualidade das interações que vivemos no mundo, ou seja, como afetamos a elas e somos afetados por elas (SANT'ANA; LOOS; CEBULSKI, 2010), sendo que os sentimentos e emoções são consequências do impacto causado em nós, em nível interno, dessas interações. Esta é uma forma holística de entender a afetividade - a "Afetividade Ampliada”, proposta por Sant'Ana-Loos e Loos-Sant'Ana (no prelo) - e que contribui para um melhor entendimento da relação entre homem e natureza. Assim, os referidos autores defendem que todos os fenômenos humanos ocorrem em uma perspectiva sistêmica, em conexão direta com os demais elementos do mundo, da Natureza. A afetividade é vista, então, como resultado dos encontros, das interações que se estabelecem com as demais coisas do mundo, sejam elas pessoas ou não. Para os autores, "tudo o que existe é resultado do tipo de afetividade que nasce das interações" (SANT'ANA; LOOS; CEBULSKI, 2010, p. 115); portanto, a existência e o movimento de qualquer ser, ou objeto, afeta o que está em sua volta. Tal concepção de afetividade vai além das definições tradicionais, unindo-se à ecologia profunda e pode ter um significativo impacto no campo epistemológico da Educação.

Considerando esta indissociável relação dos fenômenos biológicos, sociais, afetivos e cognitivos, para que a educação escolar cumpra o papel de promover o desenvolvimento integral das pessoas, é imprescindível que se deixe de focar apenas os conhecimentos e habilidades intelectuais, privilegiando sempre sua utilização na concretude no mundo exterior; mas, antes, que estes sejam integrados às habilidades sociais, pessoais, atitudes, valores, ideais (LÜCK; CARNEIRO, 1985). Tais habilidades são responsáveis pela relação com o outro, trazendo consequências importantes para nossa existência, dentro de um sistema integrado - como é a vida dentro de um pensamento sistêmico, perspectiva aqui adotada.

Tanto as emoções como os processos cognitivos têm a função de gerar atividade a partir dos acontecimentos, e a ação é essencial em qualquer relação - afinal, trata-se de uma relação. Nesta relação do eu com o outro - qualquer "outro", como defendem Sant'Ana, Loos e Cebulski (2010), incluídos aí os elementos do ambiente natural -, vemos as consequências do desrespeito à completude do ser humano, que, 
muitas vezes, não consegue sentir a emoção de viver e de se responsabilizar pela vida de outros seres, do planeta que habita, não conseguindo nem mesmo perceber que está ligado de forma irremediável à rede da vida.

\section{Percepções e representações}

A partir do momento em que assumimos que estamos mergulhados em uma "crise de percepções" (CAPRA, 1996; UNGER, 1991), devemos, mais do que nunca, resgatar o que é o ato de perceber e qual sua importância para o nosso desenvolvimento. Tradicionalmente, perceber define-se como conhecer, através dos sentidos, objetos e situações, tendo como condição necessária a proximidade do objeto no espaço e no tempo (PIAGET, 1964/2003). Por funcionar como fornecedor de informações "corretas" sobre o meio ambiente e, assim, coordenar as condutas, em estudos sobre os processos perceptivos, são sublinhados seus sentidos cognitivo e informativo (PENNA, 1993).

Contudo, a percepção não parece ser norteada somente pela cognição, até porque $o$ ato de conhecer não pode ser limitado às capacidades cognitivas. A vivência estética é um exemplo disso, pois quem vive a experiência estética "não é um sujeito que capta e conceitua objetos distantes de si, mas é o ser que se mistura às coisas e, da experiência delas, faz traduções que se compõem de algo além do conceito." (MARIN; OLIVEIRA, 2005, p.197).

A dimensão afetiva é pouco considerada nos estudos sobre percepção ambiental. Ora, se a percepção ambiental é definida como abrangendo as diferentes maneiras sensitivas pelas quais os seres humanos captam, percebem e se sensibilizam pelas realidades, ocorrências, manifestações, fatos, fenômenos, processos ou mecanismos ambientais, observados "in loco" (MACEDO, 2000), é impossível estudar e analisar essa relação sem considerar as emoções e sentimentos que a permeiam, a maneira como os elementos de uma interação se "afetam" mutuamente. Não é possível continuar seguindo um paradigma dualista - e os dualismos predispõem às dicotomias - dentro da proposta de uma educação ambiental que se dispõe a reavaliar como acontece a interação do homem com o que o cerca e redirecioná-la. Refletindo sobre o foco das pesquisas sobre percepção ambiental, Marin (2008) contribui com essa discussão, sugerindo que os estudos acerca da percepção ambiental deveriam ir para além do aporte conceitual, ir "[...] à gênese da existência e descrever os múltiplos modos de vida reveladores do real sentido de inserção do ser humano no seu ambiente." (MARIN, 2008, p. 217).

Resgata-se, aqui, portanto, o papel fundamental das representações, pois é por meio delas que conseguimos agir sobre a realidade de forma imediata (DELVAL, 1998). Afinal, são elas que nos fornecem as referências que guiam, na prática, nossas ações. Devido à importância desse novo e grande passo, que permite uma ampliação da interação do ser humano com o mundo, Reigota (1994b) alerta que a primeira providência para a realização de uma verdadeira educação ambiental é identificar as representações relativas ao ambiente das pessoas envolvidas no processo educativo, pois, a resolução dos grandes conflitos atuais depende da concepção de meio ambiente que cada um tem. Nesse sentido, é que se objetivou, no presente estudo, identificar representações e afetos relacionados à Natureza entre as crianças participantes. 


\section{Método}

O estudo, de caráter exploratório e enfoque qualitativo, caracterizou-se como uma pesquisa participante. Essa opção nos pareceu adequada ao objetivo proposto, visto que envolve uma investigação de elementos subjetivos dos participantes, cujo acesso parece ainda não ser possível por meio de instrumentos padronizados. Ocorreu em uma escola particular do município de Curitiba/PR, que oferece a $1^{\mathrm{a}}$ e a $2^{\mathrm{a}}$ série do Ensino Fundamental (atualmente, $2^{\circ}$. e $3^{\circ}$. anos, respectivamente), em período integral, em turmas separadas por sexo, onde professores homens dão aulas para os meninos e professoras mulheres dão aulas para as meninas. Por este motivo somente as meninas participaram das atividades, pois somente nas turmas femininas foi permitida a inserção da pesquisadora. A escolha da referida escola se deu pela existência de um bosque em seu terreno, cujo acesso era permitido às crianças. Os dados apresentados nesse artigo ${ }^{3}$ foram coletados durante quatro encontros de 40 minutos cada, dos quais participaram nove meninas de seis e sete anos.

Como ferramentas para a coleta de dados foram utilizadas (1) elaboração de desenhos; (2) dinâmicas de grupo; e (3) observação. As atividades desenvolvidas foram escolhidas com o objetivo de tornar "visíveis" pensamentos, opiniões e sentimentos sobre as realidades perceptíveis para elas em relação à Natureza, compreendendo (1) "Desenho da natureza"; (2) Dinâmica "Tesouro no bosque"; (3) "Todos dependem de todos" (Teia da Vida); (4) "Contando uma história". A totalidade dos encontros foi videografada para fins de registro e análise dos dados.

Foram tomados os devidos cuidados éticos durante o estudo, sendo que os pais (ou responsáveis) pelas crianças foram informados acerca do mesmo e assinaram o Termo de Consentimento Livre e Esclarecido, autorizando seus filhos a participarem. As crianças foram convidadas a tomar parte, respeitando-se o desejo de o fazerem ou não. Todas as crianças da turma participaram das atividades aqui relatadas. Com o fim de manter o seu anonimato, os nomes verdadeiros foram substituídos por nomes fictícios, escolhidos por elas próprias, como pseudônimos.

Para fins de análise do "Desenho da natureza", foram formuladas duas categorias principais para direcionar a descrição e a interpretação dos dados: (1) inserção de si no desenho (noção de pertencimento à natureza); e (2) representação (ou não) da natureza somente como ambiente natural, reproduzindo a visão naturalista. Já dentre as falas obtidas por meio das demais atividades foram selecionadas aquelas mais relevantes no sentido de se compreender as percepções trazidas pelas crianças.

\section{Resultados}

\section{Desenho da Natureza}

Esta atividade ocorreu em dois momentos: o desenho individual, no qual cada criança fez a sua representação sobre a natureza em uma folha de papel sulfite, dispondo de lápis preto e lápis de cores variadas; e, posteriormente, a montagem coletiva de um grande quadro, em papel kraft, com elementos diversos (nuvem, prédio, etc.) desenhados em papel sulfite e disponibilizados pela pesquisadora. 
A seguir são apresentados dois dos desenhos realizados de maneira a ilustrar o padrão encontrado nas representações das crianças participantes:
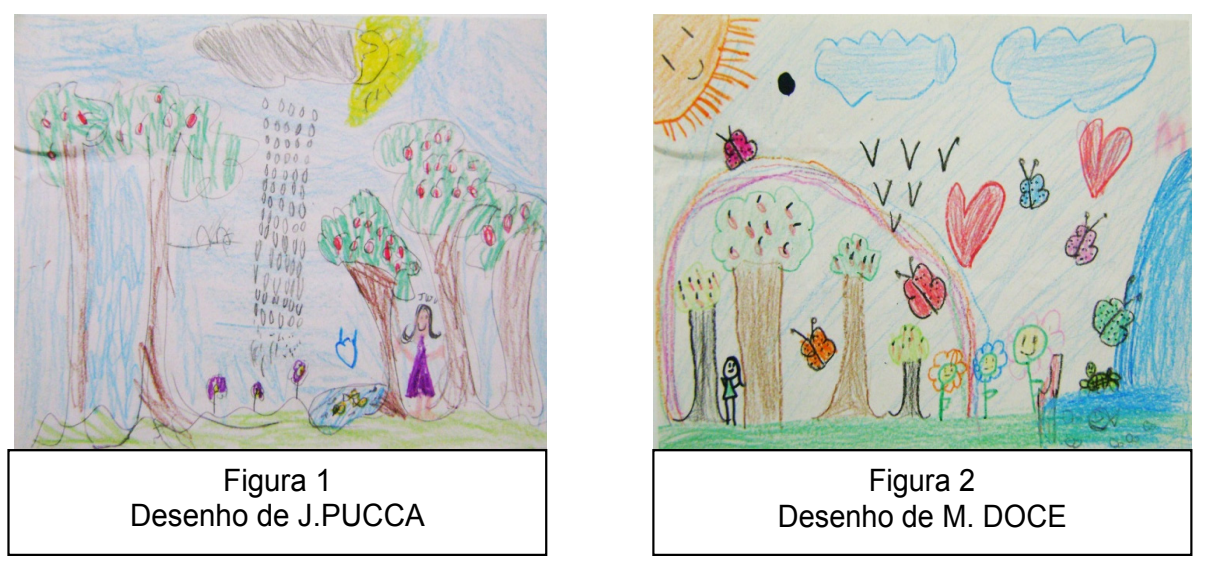

A Figura 3, a seguir, consiste em um gráfico que representa como as crianças, por meio de seus desenhos, se inseriram nas duas principais categorias de análise desta atividade: (1) a representação de si mesma, enquanto forma humana, no desenho realizado; e (2) a manifestação de uma visão naturalista da Natureza. Nota-se que seis entre as nove meninas representaram a si mesmas no desenho, indicando que a percepção predominante entre os participantes é a de que o homem, sim, faz parte da Natureza. No que diz respeito à segunda categoria de análise, observa-se que todas as crianças apresentaram uma visão naturalista da Natureza:

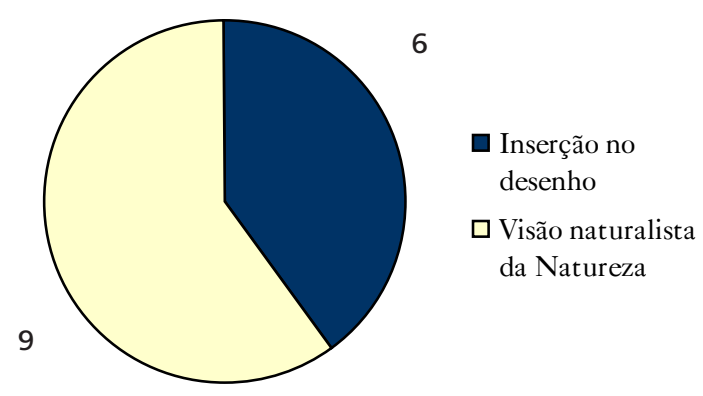

Figura 3: Gráfico representativo da análise dos desenhos feitos pelas crianças em relação às categorias inserção de si como parte da natureza e visão naturalista da natureza.

Parte-se do principio de que, nesta fase de desenvolvimento, em que as crianças participantes se encontram (transição entre o estágio pré-operatório e o operatório concreto, conforme a teoria de Piaget), existe a predominância da intuição, da criatividade e da visão subjetiva do mundo. E que, quando desenha, a criança pretende fazer o retrato mais realista possível, no qual o que reproduz da realidade é mais 
sobre o que ela "sabe" do que sobre o que ela vê (PIAGET, 1964/2003; DELVAL, 1998). Sendo o desenho uma interpretação que cria relações, constrói símbolos e revela conceitos (GOLDBERG; YUNES; FREITAS, 2005), uma representação do mundo vivido resulta da maneira como a criança "substitui" os objetos concretos com os quais interage. Foram considerados, também, como base para a análise, os estágios propostos por Luquet (PILLAR, 1996), sendo que, de acordo com este critério, as meninas participantes do estudo situam-se entre os estágios do "realismo intelectual" e do "realismo visual". Portanto, seus desenhos encontram-se entre a imaginação vivida e a lógica, podendo ser considerados como representações simbólicas que se sustentam parcialmente na fantasia, fugindo ainda um pouco da realidade concreta, mas que já posicionam os objetos a partir do entendimento de seu real lugar dentro das relações das quais fazem parte.

Sobre a manifestação de significados da vida afetiva no desenho infantil, $\mathrm{Di}$ Leo (1985) constata que as figuras de árvores, flores e o sol (elementos encarados com naturais) aparecem como expressão da necessidade de luz, natureza e um mundo que vai além do lar. Quanto a isso, é fácil resgatar lembranças pessoais bem como observar os desenhos infantis em qualquer escola e concluir sobre o significado afetivo de tais itens, dessa primária e delicada interação com o mundo, o que poderia ser mantido por muito mais tempo se cultivássemos uma visão menos antropocêntrica, se deixássemos de ensinar às crianças modelos de vida tão insustentáveis - baseados na objetivação pura e simples das coisas, e pior, dos demais seres vivos.

Reconhece-se que o fato de a maioria das crianças ter inserido a si mesma no desenho - apresentando uma concepção de que os indivíduos humanos também pertencem à Natureza - não é muito comum. É possível que isso se mostre um reflexo da situação real vivenciada por elas, que é a de estar, durante quase toda a semana imersas em um ambiente que preserva características naturais, como o bosque da escola. Oliveira (2006), em sua dissertação de mestrado sobre a relação do homem com a natureza, em uma escola que utiliza a pedagogia Waldorf (escolas onde se seguem as ideias de Rudof Steiner, segundo as quais o homem é uma síntese da Natureza), obteve como resposta das crianças vários casos de representações da Natureza com a presença da figura humana. Pode ser que, em nosso caso, como as crianças têm o privilégio de ver e vivenciar um ambiente natural diariamente, e por muitas horas, tal contato possa estar influenciando sua auto inserção no desenho.

O segundo momento desta atividade, envolveu a montagem de um quadro no qual as meninas deveriam escolher o que, segundo elas, faz parte da natureza e o que não faz. Figuras de nuvens, pássaros, borboletas, animais, água, um ser humano e um prédio foram disponibilizadas com a finalidade de que elas decidissem sobre o que faz ou não parte da Natureza. A figura, a seguir, mostra o resultado da atividade: 


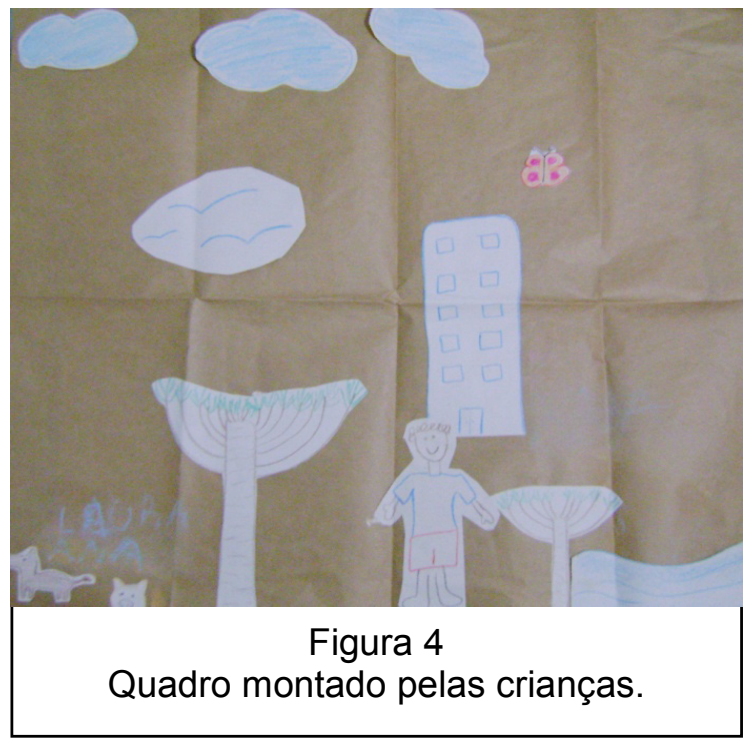

Quando o ser humano foi escolhido por L. PLANOS para ser incluído no quadro, que justificou a inclusão explicando que é "porque ele constrói as coisas e às vezes planta", A. DESENHADORA concluiu que com a intervenção humana essa natureza seria classificada como 'modificada': "só que aí seria uma natureza modificada" (sic). A partir desse ponto iniciou-se uma discussão sobre como seria classificada, então, uma cidade. Quando questionadas sobre "O que é a cidade?" A. DESENHADORA explicou que é "urbanizada" e "humanizada" (o que significa, para ela, que o ser humano "mexeu" na cidade). Ao serem perguntadas sobre o que existia no espaço da cidade antes dela ser construída, as crianças responderam que era a floresta, "o lugar onde os índios moravam”. Após essa discussão, perguntou-se finalmente se a cidade é ou não parte da Natureza, e somente A. DESENHADORA consentiu. Apesar disso, no momento em que o prédio foi escolhido para fazer parte do quadro, houve uma discussão muito agitada entre elas, pois uma delas achava que o prédio deveria fazer parte do quadro e as outras não. B. BARBIE disse que o prédio fica perto da natureza, mas não faz parte dela. Também, segundo $\mathrm{M}$. DOCE e J. PUCCA, ele não deveria fazer parte, pois foi construído pelo ser humano. A emergência do conflito mostra que a noção mais ampla de natureza, da qual o ambiente construído também faz parte, não é facilmente aceita. Isso leva a pensar que se tal postura se torna internalizada à medida que a pessoa cresce, o cuidado (o 'amor', citado por elas) que se deve ter com o ambiente natural não pode ser transferido para o artificial, gerando, desta forma, um distanciamento cada vez maior entre a sua vida cotidiana, que é vivida predominantemente no ambiente construído, e o cuidado com o meio ambiente "natural".

\section{Gincana "tesouro no bosque"}

Esta atividade teve o intuito de exercitar a observação do belo e da ressignificação dos elementos que estão presentes no dia-a-dia das crianças. Sabe-se que a experiência estética proporciona ao homem a oportunidade de se relacionar com o 
mundo que é percebido prioritariamente pela emoção e por meio de outras dimensões que fazem parte de sua construção (MARIN; OLIVEIRA, 2005). Isso apareceu fortemente no jogo proposto, já que a escolha dos tesouros foi justificada pela preferência pela forma, cor, tamanho, atributos sempre ligados a um apelo estético. Além disso, a sensibilidade relativa aos "tesouros" foi exercitada tocando nas folhas que tinham um desenho diferente, observando seus diversos tamanhos, cores e formatos. Esse é um dos exercícios de sensibilização que SARDI (1999) propõe para trabalhar com crianças, assim como realizar desenhos, esculturas, teatros, música, de maneira a deixá-las se envolver com o ambiente.

Após a exploração dos "tesouros", procedeu-se a uma discussão sobre os resíduos coletados no meio do bosque. Ao serem questionadas sobre se os resíduos podiam também ser considerados "tesouros" todas falaram que não, justificando "porque é lixo", não podendo, portanto, estar incluídos no universo simbólico construído em torno da ideia de "tesouro". Quando indagadas sobre a razão dos objetos considerados 'lixo' não deverem estar no meio do bosque (já que elas mesmas tiveram a iniciativa de retirá-los), apareceram falas como as seguintes:

\author{
J. DESENHADORA: Por que tá poluindo o ambiente. \\ B. BARBIE: Por que polui a natureza. \\ M. CONTINHA: Por que isso estraga a natureza também. \\ PESQUISADORA: E por que o lixo estraga a natureza? \\ C. DOCE: Alguns restos de comida podem virar adubo para as plantas. \\ PESQUISADORA: E o plástico vira adubo para as plantas? \\ L. PLANOS: Não, plástico fica 400 meses ali. \\ J. DESENHADORA: 400 anos! \\ PESQUISADORA: A gente vai fazer o que com esse lixo agora? \\ L. PLANOS: Jogar no lixo!
}

As participantes mostraram uma aprimorada noção de diferenciação entre materiais inorgânicos e orgânicos, bem como de seu papel dentro do ciclo natural de decomposição. O direcionamento dos resíduos para a lixeira e dos "tesouros" para o bosque transformou ideias em ação naquele momento.

Durante a atividade surgiram histórias (reais e inventadas) sobre animais que vivem no bosque, tendo sido até mesmo relatado um sonho de L. PLANOS envolvendo o bosque e o lobo que supostamente lá reside. É inegável esta ligação afetiva, que, não somente traz experiências prazerosas, mas também desafios (por vezes, desagradáveis) a serem enfrentados. Para Gadotti (2000) e Lima (1999) a sensação de pertencimento ao universo não começa na idade adulta e sim na infância; desde crianças sentimo-nos profundamente ligados a algo muito maior que o nosso ambiente imediato, ligados ao universo, e originalmente nos colocamos diante dele em um "misto de espanto e respeito". E, é este sentimento que deveria ser preservado até a vida adulta, de forma a nos tornarmos pessoas ainda conectadas à vida, esta entendida de maneira mais ampla. 


\section{Dinâmica "todos dependem de todos" (teia da vida)}

Esta dinâmica tem por objetivo tornar visível a concepção de rede, de interligações entre todos os seres, que dá base ao presente trabalho. A sequência da Teia da Vida foi seguida sem muitas complicações. As crianças, a partir de perguntadas levantadas pela pesquisadora, foram associando o próximo elemento da roda que deveria fazer parte da rede. Quando chegou no "ser humano" e todos os seres já se encontravam conectados, situações de extinção progressiva começaram a ser levantadas, até que o ser humano se visse sozinho. Este momento foi breve, porém o mais rico no sentido de alcançar o objetivo de averiguar a percepção das crianças em relação ao futuro do homem dentro de um ambiente destruído. Houve uma pequena dramatização durante a explicação das consequências da extinção. $\mathrm{O}$ mais interessante é que as crianças responderam imediatamente à mudança de "clima" neste momento: foram ficando quietas e com fisionomias tristes, ao ponto de, no final, fingirem que estavam chorando. Para fazê-las refletir um pouco mais sobre o destino do homem dentro dessa situação, foram dirigidas a elas algumas indagações:

PESQUISADORA: Vocês viram que a gente fez uma rede grande onde todo mundo está interligado?

B. BARBIE: $E$ dai a gente soltou.

M. CONTINHA: E todo mundo morreu e o ser humano ficou sozinho!

PESQUISADORA: Será que ele vai conseguir ficar sem a água, sem árvores...?

L. PLANOS: Sem a natureza ele não respira!

De fato o que mais chamou a atenção ao longo da dinâmica foi a noção de dependência do homem das condições ambientais e, consequentemente, dos outros seres vivos que se mostrou prontamente nas crianças participantes. Parece tratar-se de um sentimento, ou de uma intuição inerente às pessoas, mas que aos poucos vai sendo "assassinada" pelo paradigma vigente, o qual vai cortando a ligação que deveria, ao contrário, se tornar cada vez mais ativa, no sentido de poder se transformar em importantes ações futuras. Esse tipo de atividade atende a uma sensação de urgência nos processos educativos, urgência de que o sentimento de respeito pela vida e a consciência ecológica se tornem mais e mais abrangentes, que possibilitem uma percepção mais profunda da condição humana enquanto guardiã da vida na Terra (LIMA, 1999).

\section{Contando uma história}

A turma se organizou (espontaneamente) em dois grupos e ambos contaram sua história dentro do bosque, interagindo com árvores e plantas que lá se encontravam. O primeiro grupo acabou sendo composto somente por duas meninas, que não contaram propriamente uma "história", preferindo discorrer sobre as características dos macacos e das tartarugas. O segundo grupo reuniu as demais participantes e interpretou uma conversa entre dois macacos, uma aranha e uma borboleta, que conversavam sobre bananas, filhotes e teias de aranha. Como é bem típico da idade, esse grupo atribuiu fala aos animais escolhidos, porém elencou características dos próprios animais e não características humanas, como é o mais comum.

A atividade foi denominada, pelas crianças, "teatrinho" e teve o intuito de levá-las a vivenciar o bosque de uma forma diferente. O bosque é um espaço que, 
conforme Piaget (1975, p. 404-405; em GUIMARÃES, STOLTZ, 2008), é composto pelos cenários das experiências humanas, sentidos e compreendidos de maneiras individualmente distintas por meio de vínculos tanto afetivos quanto cognitivos, e através de mecanismos perceptivos que vão se estabelecendo com o tempo. A possibilidade de obter novas experiências, como contar uma história encontrando-se envolvidas pelo bosque, tem por objetivo tornar evidente essa relação e dela fazer emergir representações, já que este espaço e seus componentes acabam sendo palco para mais uma vivência, para mais uma memória; ou seja, torna-se parte do processo de ressignificação constante que acontece entre o ambiente e a pessoa. A atividade realizada ainda buscou possibilitar a criação de um ambiente lúdico que proporcionasse segurança psicológica e, ao mesmo tempo, despertasse o talento criativo. Ainda, a vivência estética foi um ponto de apoio para as atividades, pois quem vive a experiência estética "não é um sujeito que capta e conceitua objetos distantes de si, mas é o ser que se mistura às coisas e, da experiência delas, faz traduções que se compõem de algo além do conceito." (MARIN, OLIVEIRA, 2005, p.197).

\section{Considerações finais}

A questão ambiental deve ser compreendida como um produto da intervenção da sociedade sobre a Natureza e diz respeito não apenas aos "problemas relacionados à Natureza", mas às problemáticas decorrentes da ação social (SARDI, 1999). A crise, que se pressupunha ser meramente ecológica, foi rebatizada pelos estudos ambientais como uma problemática de proporção planetária que é, a um só tempo, social, cultural, biológica, econômica, política, ética e educativa (SILVA, 2007). Tal perspectiva de desenvolvimento acabou desencadeando um movimento multidimensional que problematiza as formas de produção, os estilos de vida e as orientações do conhecimento científico-tecnológico, assim como os conteúdos da educação formal e não-formal (LEFF, 2000b).

A humanidade tem feito alguns progressos, porém, ainda nos encontramos muito longe de encontrar soluções efetivas para o complexo problema que temos em mãos. Contudo, a simples compreensão da Natureza como um imenso ciclo organizado no qual se insere a nossa própria espécie pode em muito ajudar a recuperar um novo sentido de liberdade. Uma liberdade menos egoísta e mais solidária, menos restrita ao ego humano e mais voltada à harmonia do universo (MANTOVANI, 2009).

Como se pretendeu mostrar aqui, todo o trabalho com as crianças participantes do estudo buscou fazê-las externalizar e, até mesmo, recriar significados sobre os objetos e seres que elas entendiam como sendo "natureza". Foi possível também observar indicativos da ligação intrínseca entre as crianças e a 'vida', sendo inevitável notar o elo topofílico e biofílico (HUTCHISON, 2000) entre elas e o bosque. Medir "cientificamente" os resultados dos esforços neste tipo de trabalho de sensibilização, na escola, não é uma tarefa assim tão fácil, e, para tanto seria necessário um tempo bem maior de acompanhamento e intervenção junto às crianças. No entanto, tomando por base as referências consultadas, bem como a certeza de que alguns valores diferentes destes que predominam hoje em nossa sociedade precisam ser apresentados às nossas crianças, acredita-se que exercícios desse tipo contribuam para a construção de outra relação - mais respeitosa - com o espaço e com os demais seres vivos. 
Pode-se dizer, então, que tais tipos de atividades são de inegável riqueza para que projetos de educação ambiental, ou que tomam parte de qualquer outra pedagogia, tentem atingir seu objetivo principal, que é - ou pelo menos deveria ser -o de mediar a vida a partir de princípios sustentáveis. Apresentamos, aqui, o apelo de que possamos aprender e ensinar as novas gerações a prestar mais atenção e respeito às variadas possibilidades de interação que existem no mundo, a cuidar com a maneira como cada coisa afeta e é afetada pelas demais, e que não desistamos, nunca, de almejar a homeostase, o equilíbrio em cada uma delas. Afinal, como se diz, até o bater de asas de uma borboleta pode mudar o destino de um sistema!

\section{Referências}

CAPRA, F. A teia da vida: uma nova compreensão científica dos sistemas vivos. Tradução de: EICHEMBERG, Newton Roberval. São Paulo: Cultrix, 1996.

Como a natureza sustenta a Teia da Vida. In: STONE, K. M.; BAELOW, Z.

(Orgs.) Alfabetização Ecológica: A educação das crianças para o mundo sustentável. Tradução de: FISCHER, Carmem, São Paulo: Cultrix, 2006. Prólogo, p. 9 -12.

DELVAL, J. Crescer e pensar: a construção do conhecimento na escola. Porto Alegre: Artes Médicas, 1998.

Di LEO, J. H. A interpretação do desenho infantil. Porto Alegre: Artes Médicas, 1985.

FREITAS, C. M. Problemas ambientais, saúde coletiva e ciências sociais. Ciência \& Saúde Coletiva, 8(1): 1337-150, 2003. Disponível em: <http://www.scielo.br/scielo.php?pi$\mathrm{d}=\mathrm{S} 141381232003000100011 \&$ script=sci_abstract\&tlng=pt. $>$. Acesso em: 24/06/2010.

GADOTTI, M. Pedagogia da terra. São Paulo: Peirópolis, 2000.

GOLDBERG, L. G.; YUNES, M. A. M.; FREITAS, J. V. O desenho infantil na ótica da ecologia do desenvolvimento humano. Psicologia em Estudo, Maringá, v. 10, n. 1, p. 97-106, jan./abr. 2005. Disponível em: <www.scielo.br/pdf/pe/v10n1/v10n1a11.pdf>. Acesso em: 05/04/2010.

GONÇALVES, J. C. Homem-natureza: uma relação conflitante ao longo da história. Saber Acadêmico, São Paulo, n. 6, p. 171-177, dez. 2008.

GUIMARÃES, S. R. K.; STOLTZ, T. (Orgs.). Tomada de consciência e conhecimento metacognitivo. Curitiba: UFPR, 2008.

HUTCHISON, D. Educação ecológica. Tradução de: Batista, Dayse. Porto Alegre: Artes Médicas, 2000.

LEFF, E. Ecologia, capital e cultura: racionalidade ambiental, democracia participativa e desenvolvimento sustentável. Blumenau: EdiFurb, 2000a.

LEFF, E. Pensamento sociológico, racionalidade ambiental e transformações do conhecimento. Epistemologia Ambiental. São Paulo: Cortez, 2000b. p. 109-157.

LEFF, E. Saber ambiental: sustentabilidade, racionalidade, complexidade e poder. Petrópolis, Rio de Janeiro: Vozes, 2001.

LEFF, E. Racionalidade ambiental e a reapropriação social da natureza. Rio de Janeiro: Civilização Brasileira, 2006.

LIMA, I. Resumos do Primeiro Encontro Internacional da Carta da Terra na perspectiva da educação. São Paulo: Instituto Paulo Freire, 1999.

LÜCK, H.; CARNEIRO, D. G. Desenvolvimento afetivo na escola: promoção, medida e avaliação. 2a . Ed. Petrópolis: Vozes, 1985. 
MACEDO, R. L. G. Percepção e conscientização ambiental. Lavras, Minas Gerais: UFLA/ FAEPE. 2000.

MARIN, A. A. Pesquisa em educação ambiental e percepção ambiental. Pesquisa em Educação Ambiental, vol. 3, n. 1, p. 203-222, 2008. Disponível em: <http://www.revistasusp.sibi.usp.br/ pdf/pea/v3n1/12.pdf>. Acesso em: 24/06/2010.

MARIN, A. A.; OLIVEIRA, L. C. B. A experiência estética em Dufrenne e Quintás e a percepção de natureza: para uma educação ambiental com bases fenomenológicas. Revista Eletrônica - Mestrado em Educação Ambiental, Rio Grande, v. 15, p. 196-210, jul. 2005. Disponível em:< ww.remea.furg.br/edicoes/vol15/art15.pdf>. Acesso em: 24/06/2010

MONTOVANI, W. Relação homem e natureza: raízes do conflito. Gaia Scientia, São Paulo v 3, n. 1, p. 3-10, 2009.

OATLEY, K.; JENKINS, J. M. Compreender as emoções. Porto Alegre: Instituto Piaget, 2002.

OLIVEIRA, F. M. C. A relação entre homem e natureza na pedagogia Waldorf. 193 p. Dissertação de Mestrado não publicada. Pós-Graduação em Educação, Universidade Federal do Paraná, Curitiba, 2006.

ORR, D. W. Prólogo. In: STONE, K. M.; BAELOW, Z. (Orgs.) Alfabetização ecológica: a educação das crianças para o mundo sustentável. Tradução de: FISCHER, Carmem, São Paulo: Cultrix, 2006a, p. 9-12.

ORR, D. W. Lugar e pedagogia. In: STONE, K. M.; BAELOW, Z. (Orgs.) Alfabetização ecológica: a educação das crianças para o mundo sustentável. Tradução de: FISCHER, Carmem, São Paulo: Cultrix, 2006b.

PENNA, A. G. Percepção e realidade. 2 ed. Rio de Janeiro: Imago, 1993.

PIAGET, J. Seis estudos de psicologia. 24a ed. Forense Universitária, 1964/2003.

PILLAR, A. D. Desenho e construção de conhecimento na criança. Porto Alegre: Artes Médicas, 1996.

REIGOTA, M. Meio ambiente e representação social. São Paulo: Cortez, 1994a.

REIGOTA, M. O que é educação ambiental? São Paulo: Brasiliense, 1994b.

SANT'ANA, R. S.; LOOS, H.; CEBULSKI, M. C. Afetividade, cognição e educação: ensaio acerca da demarcação de fronteiras entre os conceitos e a dificuldade de ser do homem. Educar em Revista, n. 36, p. 109-124, 2010.

SANT'ANA-LOOS, R. S.; LOOS-SANT'ANA, H. Afetividade Ampliada (I): a (re)construção do conhecimento sob os princípios da psique e do que nos faz humanos. Curitiba: Juruá, 2013 [no prelo].

SARDI, S. Linhas inspiradoras para uma educação ambiental infantil. In PELIZZOLI, M. A emergência do paradigma ecológico. São Paulo: Vozes, 1999.

SILVA, A. T. O campo epistemológico da educação ambiental: o dualismo homem/natureza e o paradigma da complexidade. 301 p. Tese de Doutorado não publicada. Doutorado em Meio Ambiente e Desenvolvimento, Universidade Federal do Paraná, Curitiba, 2007.

TUAN, Y. F. Topofilia: um estudo da percepção, atitude e valores do meio ambiente. Tradução de: Lívia de Oliveira. São Paulo: Difel, 1980.

UNGER, N. M. O encantamento do humano: ecologia e espiritualidade. Edições Loyola: São Paulo, 1991. 


\section{Notas}

${ }^{1} \mathrm{O}$ presente trabalho apresenta parte da monografia realizada junto ao Curso de Especialização em Meio Ambiente e Desenvolvimento da Universidade Federal do Paraná pela segunda autora, orientada pela primeira autora.

${ }^{2}$ Incluam-se neste universo a alfabetização ecológica, a ecopedagogia, a educação biocêntrica.

${ }^{3} \mathrm{O}$ estudo completo foi desenvolvido em cinco sessões, dentre as quais foram selecionadas quatro para descrição e análise no presente trabalho.

* Professora Doutora da Universidade Federal do Paraná, Curitiba, Paraná - Brasil.

*** Mestre em Educação pela Universidade Federal do Paraná, Curitiba, Paraná - Brasil.

\section{Correspondência}

Helga Loos-Sant'Ana - Universidade Federal do Paraná, Setor de Educação, Departamento de Teoria e Fundamentos da Educação. Rua General Carneiro, 460, Centro, CEP: 80060-150 - Curitiba, Paraná Brasil.

E-mail: helgaloos@yahoo.com.br - cambiental@gmail.com

Recebido em 25 de maio de 2013

Aprovado em 07 de setembro de 2013 